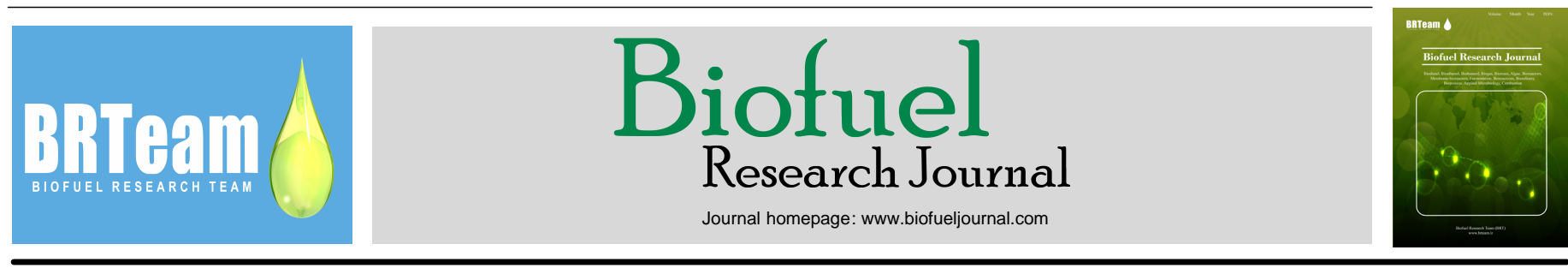

Original Research Paper

\title{
Simultaneous biosorption and bioethanol production from lead-contaminated media by Mucor indicus
}

\author{
Saman Samadi ${ }^{1}$, Keikhosro Karimi $^{1,2, *}$, Sanaz Behnam ${ }^{1}$ \\ ${ }^{1}$ Department of Chemical Engineering, Isfahan University of Technology, Isfahan 84156-83111, Iran. \\ ${ }_{2}^{2}$ Industrial Biotechnology Group, Research Institute for Biotechnology and Bioengineering, Isfahan University of Technology, Isfahan 84156-83111, Iran.
}

\section{HIGHLIGHTS}

$>$ Simultaneous ethanol production and $\mathrm{Pb}^{2+}$ biosorption by Mucor indicus live biomass was investigated.

$>$ Cultivation performed within five consecutive stages.

$>$ Different morphologies of Mucor indicus were cultivated in the presence of $\mathrm{Pb} 2+$

$>$ Ethanol yields of all morphologies were lower than those on lead-free media.

$>$ The highest ethanol yields of 0.46 and $0.35 \mathrm{~g}$ ethanol/g consumed glucose were obtained by the mostly filamentous morphology.

\section{GRAPHICAL ABSTRACT}

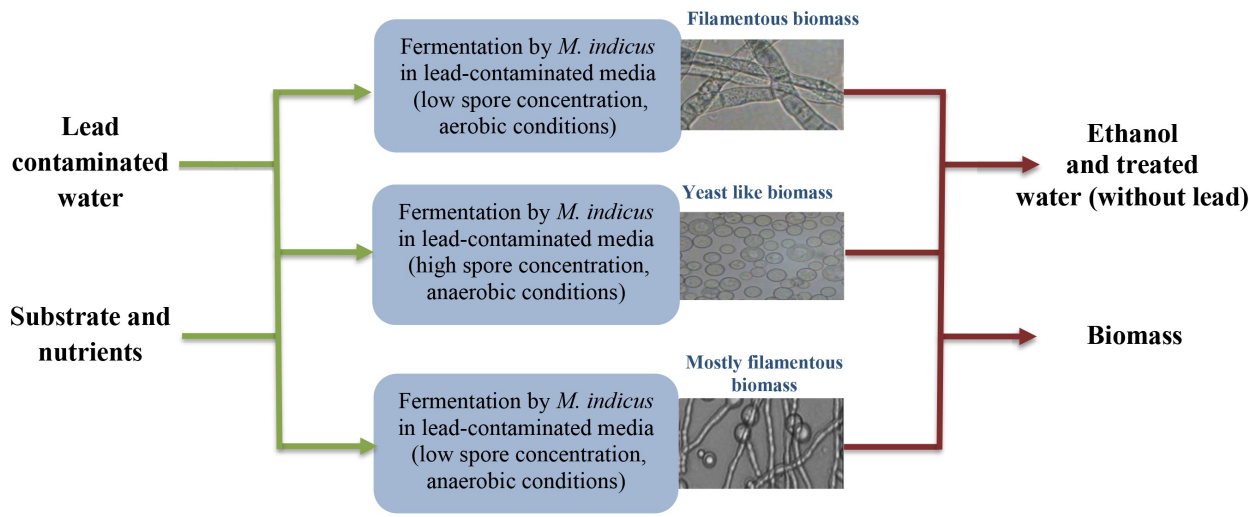

\section{ARTICLE INFO}

\section{Article history:}

Received 5 January 2017

Received in revised form 20 February 2017

Accepted 25 February 2017

Available online 1 March 2017

\section{Keywords:}

Bioethanol

Biosorption

Lead contamination

Morphology

Mucor indicus

\begin{abstract}
Mucor indicus with different morphologies was used for ethanol production and $\mathrm{Pb}^{2+}$ biosorption. With increasing $\mathrm{Pb}^{2+}$ concentration in the cultivation medium, the fungus morphology changed from purely filamentous to mostly filamentous and the biosorption capacity was increased. The maximum adsorption capacity predicted by Langmuir model was $118 \mathrm{mg} / \mathrm{g}$ for purely filamentous form. All morphologies were also cultivated in the presence of high $\mathrm{Pb}^{2+}$ concentration $(300 \mathrm{mg} / \mathrm{L})$ in consecutive stages. After the first stage of cultivation, the live biomass was separated and cultivated in a new medium similar to the first stage and cultivation was performed within five stages. All morphologies of $M$. indicus were able to grow and produce ethanol in the presence of lead at all stages but with lower yields than those cultivated in the absence of lead. The highest ethanol yields of 0.46 and $0.35 \mathrm{~g}$ ethanol $/ \mathrm{g}$ consumed glucose were obtained by mostly filamentous morphology at the first and the last stages, respectively. The presence of lead decreased the glucose consumption rate of all morphologies and the yeast-like morphology consumed glucose within a shorter time than the other morphologies. Different morphologies were able to adsorb lead ions considerably $(97-99 \%)$ within the five consecutive stages.
\end{abstract}

* Corresponding author at: Tel.: +983113915623

E-mail address: karimi@cc.iut.ac.ir

Please cite this article as: Samadi S., Karimi K., Behnam S. Simultaneous biosorption and bioethanol production from lead-contaminated media by Mucor indicus. Biofuel Research Journal 13 (2017) 545-550. DOI: 10.18331/BRJ2017.4.1.4 


\section{Introduction}

Energy crises caused by shortage of oil sources, increasing emission of greenhouse gases (GHGs), and global warming have stimulated industrial countries to seek renewable sources of energy (Fasahati et al., 2015; Hosseinpour et al., 2016). Bioethanol is considered a promising alternative for fossil fuels, as it is inexpensive, biodegradable, environmentally-friendly, and its application could partially decrease GHGs generated in combustion processes (Bateni et al., 2014; Karimi and Chisti, 2015; Aghbashlo et al., 2016).

On the other hand, the growing industrial and human activities continuously release high amounts of pollutants such as heavy metals into the environment. The presence of heavy metals in industrial effluents is considered as a serious threat to human life and the environment, since they are toxic and non-biodegradable, and dangerously accumulate in the food chain and human body (Çeribasi and Yetis, 2001). Lead is available in effluents of different industries such as battery manufacturing, printing and pigment, glass, and ceramics. Lead concentrations higher than $0.05 \mathrm{mg} / \mathrm{L}$ in drinking water could cause health effects such as anemia and encephalopathy (Yan and Viraraghavan, 2003). Therefore, it is important to remove this ion from industrial wastewaters to ensure their safe disposal. There are several methods for heavy metals removal from wastewater, including chemical precipitation, membrane separation, ion exchange, and reverse osmosis (Guibal et al., 1992). All these conventional methods are expensive and inefficient at low metal ions concentrations (1-100 mg/L) (Majumdar et al., 2010). Recently, adsorbents of biological origin have been considerably used for heavy metals removal, which are easily available, inexpensive, and effective for dilute streams (Yan and Viraraghavan, 2001; Shroff and Vaidya, 2012; Aryal and Liakopoulou-Kyriakides, 2014).

In recent years, fungi have been widely used for treatment of wastewaters (Emtiazi et al., 2001; Yan and Viraraghavan, 2003). Mucor indicus is a dimorphic fungus which can grow in filamentous, yeast-like, or their mixture under both aerobic and anaerobic conditions. Different factors such as spore concentration, sugar concentration, atmospheric conditions, and medium composition would affect the fungal morphology (Karimi and Zamani, 2013). $M$. indicus cell wall contains a considerable amount of chitosan, a biodegradable polysaccharide containing amino and hydroxyl groups. Therefore, the biomass of the fungus is a suitable adsorbent for heavy metal removal (Behnam et al., 2015a). Accordingly, dead biomass of this fungus has been used for bioremediation in number of studies and its considerable biosorption capability of heavy metals has been proven (Yan and Viraraghavan, 2003; Javanbakht et al., 2011). However, the live biomass of this fungus has not been evaluated for bioremediation.

On the other hand, this fungus has been recently used for ethanol production and it has been shown that the yield of ethanol production by $M$. indicus in media containing no heavy metal was high and comparable to the yield of the microorganisms industrially used for bioethanol production (Shafiei et al., 2011; Satari et al., 2012).

In this study, different morphologies of $M$. indicus were cultivated in media containing lead ions to investigate the fungal growth, which is normally accompanied by ethanol production. In better words, $M$. indicus live biomass capability to adsorb lead ions $\left(\mathrm{Pb}^{2+}\right)$ and simultaneously produce ethanol in contaminated media was investigated. To the best of our knowledge, there is no report looking into simultaneous bioethanol production and heavy metal removal. Furthermore, the fungus was cultivated through five consecutive stages in the presence of a high lead concentration $(300 \mathrm{mg} / \mathrm{L})$, and the performance of the fungus with different morphologies was compared. It is worth quoting that high water consumption, a typical problem in ethanol production processes, may be overcome by using wastewaters in ethanol production.

\section{Materials and Methods}

\subsection{Cultivation of $M$. indicus in one stage}

The dimorphic fungus $M$. indicus was obtained from the Culture Collection University of Göteborg (Sweden) and grown on plates containing glucose (40 $\mathrm{g} / \mathrm{L})$, peptone $(10 \mathrm{~g} / \mathrm{L})$, and agar $(20 \mathrm{~g} / \mathrm{L})$ at $32^{\circ} \mathrm{C}$ for $5 \mathrm{~d}$. The biomass of the fungus was prepared in $500 \mathrm{ml}$ Erlenmeyer flasks with $250 \mathrm{~mL}$ of a liquid mixture containing (g/L): $50 \mathrm{~g}$ glucose monohydrate, $5 \mathrm{~g}$ yeast extract, 7.5 $\mathrm{g}\left(\mathrm{NH}_{4}\right)_{2} \mathrm{SO}_{4}, 0.75 \mathrm{~g} \mathrm{MgSO}_{4} .7 \mathrm{H}_{2} \mathrm{O}, 3.5 \mathrm{~g} \mathrm{~K}_{2} \mathrm{HPO}_{4}$, and $1.0 \mathrm{~g} \mathrm{CaCl}_{2} .2 \mathrm{H}_{2} \mathrm{O}$. In order to prepare the media containing different $\mathrm{Pb}^{2+}$ concentrations, the required amount of $\mathrm{Pb}\left(\mathrm{NO}_{3}\right)_{2}$ was dissolved in the media.

Different morphologies of the fungus were induced using various initial spore concentrations and aerobicity during germination of the spores (Sharifia et al., 2008). Purely filamentous form was obtained in cotton-plugged Erlenmeyer flasks with $(3 \pm 1) \times 10^{4}$ spores $/ \mathrm{mL}$ under aerobic conditions. In order to provide the mostly filamentous form, the medium was inoculated with $(3 \pm 1) \times 10^{4}$ spores $/ \mathrm{mL}$ and a loop trap was used. Pure nitrogen gas was introduced into the medium to provide anaerobic conditions and sterile water was kept in the loop trap to prevent back-diffusion of air and to permit $\mathrm{CO}_{2}$ to exit (Javanbakht et al., 2011). The biomass with yeast-like form was prepared by cultivation under anaerobic conditions with a high spore concentration $\left((6 \pm 1) \times 10^{6}\right.$ spores $/ \mathrm{mL})$. The medium $\mathrm{pH}$ was adjusted at 5.0-5.5 using $(1 \mathrm{M}) \mathrm{H}_{2} \mathrm{SO}_{4}$ and $(1 \mathrm{M}) \mathrm{NaOH}$ solutions, and the flasks were kept in a shaker incubator at $32{ }^{\circ} \mathrm{C}$ and $130 \mathrm{rpm}$ for $24 \mathrm{~h}$. Afterwards, the biomass was separated through centrifugation (4000 rpm, $5 \mathrm{~min}$ ), washed three times with distilled water, and freeze-dried. The medium was analyzed to determine lead concentration. A light microscope (BM-22h, Isfahan Optics Industries, Iran) with a magnification of $400 \times$ was used to study the fungus morphologies obtained at different spore concentrations and aerobicity.

\subsection{Cultivation of $M$. indicus in five stages}

M. indicus was cultivated in five consecutive stages. Different media were prepared and the three morphologies of $M$. indicus were cultivated in the absence and presence of $300 \mathrm{mg} / \mathrm{L}$ lead ions for $24 \mathrm{~h}$. Afterwards, the produced biomass was separated from the cultivation medium by centrifugation (4000 rpm, $5 \mathrm{~min}$ ), transferred to the second medium, which was prepared exactly similarly to the first stage but without spores, and cultivated for $24 \mathrm{~h}$. Then, the biomass was separated again and used in the next stage of cultivation. The cultivation was performed in five stages and at the end of the fifth stage, the biomass was separated and freeze-dried. Lead concentration in the medium was measured at the end of the stages. The time for complete consumption of glucose, the amount of the produced biomass, and the ethanol yield were measured in the first and the last stages of cultivation.

\subsection{Extraction of fungal cell wall}

In order to provide fungal cell wall, each $\mathrm{g}$ of freeze-dried biomass obtained from the first stage was mixed with $30 \mathrm{~mL}$ of $0.5 \mathrm{M} \mathrm{NaOH}$ and autoclaved at $121{ }^{\circ} \mathrm{C}$ for $20 \mathrm{~min}$. Subsequently, the mixture was cooled and the alkali insoluble material (AIM) was separated through centrifugation (4000 rpm, $10 \mathrm{~min}$ ), washed with distilled water several times to neutral $\mathrm{pH}$, and freeze-dried.

\subsection{Effect of lead on the morphology and characteristics of the fungus}

To investigate the effect of the presence of lead on the morphology of $M$. indicus, several cultivation media with a concentration of $(3 \pm 1) \times 10^{4}$ spores/mL under aerobic conditions and lead concentrations of $0,10,150$, 350,400 , and $1000 \mathrm{mg} / \mathrm{L}$ were prepared, and the fungal morphology was studied after $24 \mathrm{~h}$. Furthermore, the effect of lead on the fungal composition (protein content of the biomass as well as phosphate, glucosamine, and $\mathrm{N}$-acetyl glucosamine contents of the cell wall) was studied by comparing the fungi cultivated in a lead-free medium and in a medium containing $10 \mathrm{mg} \mathrm{Pb}{ }^{2+} / \mathrm{L}$

\subsection{Adsorption isotherms}

Adsorption isotherms were studied through preparing media containing different concentrations of lead ions (i.e., 50, 100, 150, 200, 250, and 300 $\left.\mathrm{mg} \mathrm{Pb}^{2+} / \mathrm{L}\right)$. The media were inoculated with $(3 \pm 1) \times 10^{4}$ spores $/ \mathrm{mL}$ under aerobic conditions, and the lead concentration was measured after $24 \mathrm{~h}$.

Adsorption isotherms were evaluated using Langmuir and Freundlich models. Langmuir model assumes the formation of a monomolecular 
layer with no interaction between the adsorbed molecules (Aksu, 2002), while Freundlich model is a multi-site adsorption isotherm for heterogeneous surfaces (Lièvremont et al., 1998).

The linear form of Langmuir model is as follows (Eq. 1) (Aksu, 2002):

$\frac{1}{q_{e}}=\frac{1}{q_{\max }}+\frac{1}{q_{\max } K C_{e}}$

where $q_{e}$ is the equilibrium adsorption capacity which is the amount of lead ions adsorbed by unit mass of the biomass, $C_{e}$ is the equilibrium concentration, $K(\mathrm{~L} / \mathrm{mg})$ is the model constant, and $q_{\max }(\mathrm{mg} / \mathrm{g})$ is the amount of adsorbed ions to saturate unit mass of the adsorbent.

The linear form of Freundlich model is shown below (Eq. 2) (Lièvremont et al., 1998):

$\ln q_{e}=\ln K_{F}+\frac{1}{n} \ln C_{e}$

where $K_{F}\left((\mathrm{mg} / \mathrm{g}) /(\mathrm{mg} / \mathrm{L})^{1 / \mathrm{n}}\right)$ and $n$ show the capacity and intensity of adsorption, respectively.

2.6. Determination of glucosamine, $\mathrm{N}$-acetyl glucosamine, phosphates, and proteins

Glucosamine and $\mathrm{N}$-acetyl glucosamine contents of the fungal biomass AIM were determined to estimate the chitin and chitosan contents of the cell wall according to the method presented by Mohammadi et al. (2012). A combination of a two-step sulfuric acid hydrolysis and nitrous acid degradation that produces 2,5-anhydromannose and acetic acid was applied. The concentrations of anhydromannose and acetic acid were measured by HPLC with an Aminex HPX-87H column (Bio-Rad, Richmond, USA) at 60 ${ }^{\circ} \mathrm{C}$ with $0.6 \mathrm{~mL} / \mathrm{min}$ eluent of $5 \mathrm{mmol} / \mathrm{L}$ sulfuric acid. The anhydromannose was measured by chromatogram prepared by RI detector (Jasco International CO., Tokyo, Japan), while acetic acid was monitored by UV detector (Jasco International CO., Tokyo, Japan).

The phosphate content of AIM was measured by a spectrometric method. The absorbance of a blue complex obtained by mixing the hydrolysate of the biomass with ascorbic acid and ammonium molybdate reagent was measured at $880 \mathrm{~nm}$ according to European Standard ISO 6878 (Naghdi et al., 2014).

The protein content of biomass was measured based on the Biuret method (Verduyn et al., 1990). The freeze-dried biomass $(0.01 \mathrm{~g})$ was mixed with 3 $\mathrm{mL}$ of $\mathrm{NaOH}$ solution $(1 \mathrm{~mol} / \mathrm{L})$ for $2 \mathrm{~h}$ at room temperature. Afterwards, the mixture was placed in boiling water for $10 \mathrm{~min}$ and cooled immediately in an ice bath. An amount of $1 \mathrm{~mL}$ of $2.5 \% \mathrm{CuSO}_{4} .5 \mathrm{H}_{2} \mathrm{O}$ was mixed with the sample for $5 \mathrm{~min}$. The mixture was then centrifuged (4000 rpm, $4 \mathrm{~min}$ ), and the absorbance of supernatant was measured at $555 \mathrm{~nm}$ after $15 \mathrm{~min}$.

\subsection{Determination of glucose, ethanol, and lead ions concentrations}

Glucose and ethanol concentrations in the medium were measured by HPLC using an Aminex HPX-87H column (Bio-Rad, Richmond, USA) equipped with a RI detector (Jasco International CO., Tokyo, Japan) at $60{ }^{\circ} \mathrm{C}$, using $0.6 \mathrm{~mL} / \mathrm{min}$ of $5 \mathrm{mmol} / \mathrm{L}$ sulfuric acid as an eluent.

Lead ions concentration was measured by an atomic absorption spectrophotometer (210VGP, Buck Scientific Co., England). Equilibrium adsorption capacity $\left(q_{e}\right)$ was calculated as follows (Eq. 3):

$q_{e}=\frac{\left(C_{0}-C_{e}\right) V}{m}$

where $C_{0}$ and $C_{e}(\mathrm{mg} / \mathrm{L})$ are the initial and the final concentrations of lead ions, respectively, $m(\mathrm{~g})$ is the mass of the biomass, and $V(\mathrm{~L})$ is the solution volume.

\section{Results and Discussion}

\subsection{Induction of different morphologies}

The fungus was inoculated with various spore concentrations under two different atmospheric conditions (aerobic or anaerobic) to obtain different morphologies of $M$. indicus. At low spore concentration $\left((3 \pm 1) \times 10^{4}\right.$ spores $/ \mathrm{mL}$ ) under aerobic conditions, the fungus grew in purely filamentous form (Fig. 1A). With the same spore concentration $((3 \pm 1) \times$ $10^{4}$ spores $/ \mathrm{mL}$ ) under anaerobic conditions, filamentous form was obtained with some yeast-like cells (Fig. 1B), while at the high spore concentration of $(6 \pm 1) \times 10^{6}$ spores $/ \mathrm{mL}$ under anaerobic conditions, purely yeast-like form was observed (Fig. 1C). Similar morphologies under the same conditions were reported for $M$. indicus in the previous studies (Sharifia et al., 2008; Lennartsson et al., 2009).
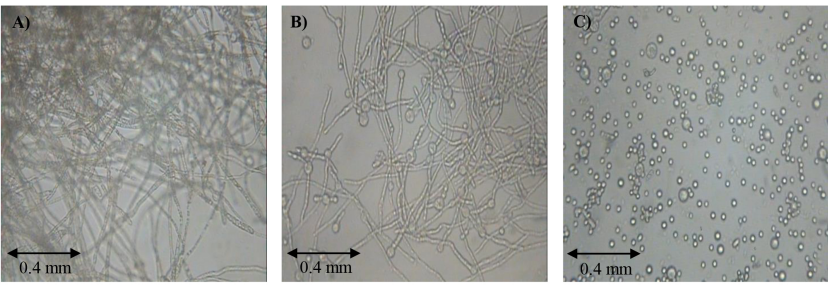

Fig.1. Different morphologies of $M$. indicus: A) purely filamentous form, B) mostly filamentous form, and $\mathbf{C}$ ) purely yeast-like form.

\subsection{Effect of lead on the morphology and characteristics of the fungus}

Effect of the presence of lead ions in the medium on the morphology of the fungus is shown in Figure 2. At a low $\mathrm{Pb}^{2+}$ concentration $(10 \mathrm{mg} / \mathrm{L})$, $M$. indicus morphology was similar to that cultivated in the absence of lead, which was purely filamentous. The morphology was changed from purely filamentous to mostly filamentous form by increasing lead concentration to $1000 \mathrm{mg} / \mathrm{L}$. Therefore, M. indicus morphology was affected by the presence of lead as a pollutant in the cultivation medium, while lead did not inhibit the growth (see Section 3.3).
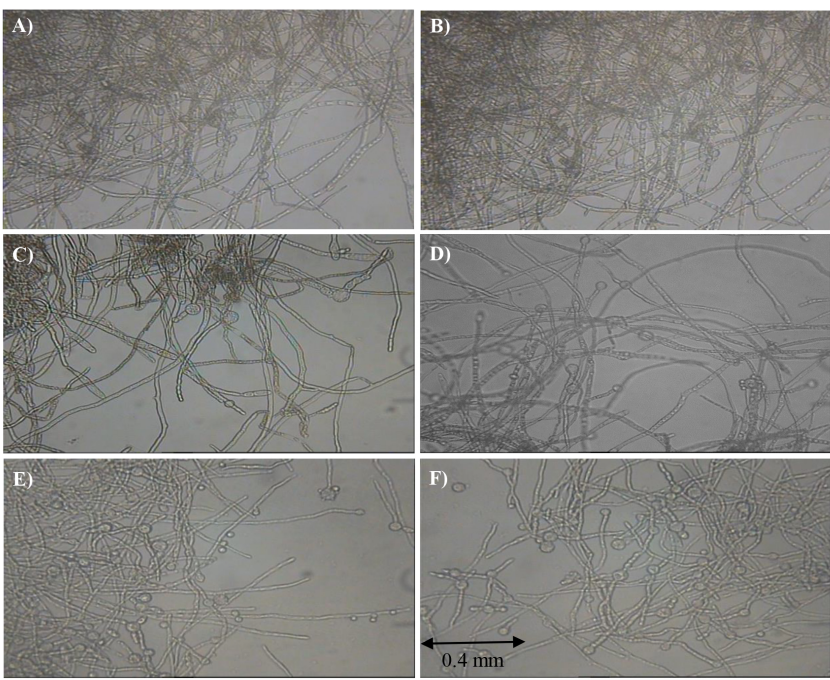

Fig.2.M. indicus morphologies in the presence of different lead concentrations ( $\mathrm{mg} / \mathrm{L}$ ): A) 0 , B) 10 , C) 150 , D) 350 , E) 400, and F) 1000 .

To the best of our knowledge, there is no study on the effect of heavy metals on fungus morphology, while it has been reported that $M$. indicus morphology is highly affected by the presence of some compounds such as $\mathrm{CO}_{2}, \mathrm{O}_{2}$, and EDTA (Bartnicki-Garcia and Nickerson, 1962; Orloski, 1991). Bartnicki-Garcia and Nickerson (1962) cultivated M. indicus under 3 different atmospheres (air, $\mathrm{CO}_{2}$, and $\mathrm{N}_{2}$ ). They observed that the presence of oxygen decreased the amount of biomass produced and the presence of $\mathrm{CO}_{2}$ changed the morphology from filamentous to yeast-like form Furthermore, cultivation in the presence of air or $\mathrm{N}_{2}$ developed the growth of the filamentous form. $M$. indicus was also grown in the presence of 
ETDA (Bartnicki-Garcia and Nickerson, 1962). The results showed that the fungus morphology changed from yeast-like to filamentous form in the presence of EDTA. On the other hand, the presence of EDTA in the range of $2.7 \times 10^{-5}$ to $27 \times 10^{-4} \mathrm{M}$ showed inhibitory effects on the fungus growth.

The effect of lead on the biomass and the cell wall composition was also studied and the results are presented in Table 1 . Accordingly, the presence of $10 \mathrm{mg} / \mathrm{L}$ of lead ions in the medium in which the fungus was grown did not affect the fungal characteristics. The protein and $\mathrm{N}$-acetyl glucosamine contents of the fungus cultivated in a lead-free medium were $0.51(\mathrm{~g} / \mathrm{g}$ biomass) and 0.21 (g/g AIM), respectively, which were in agreement with the results reported by other researchers in the absence of heavy metals (Mohammadi et al., 2012 and 2013).

Table 1.

Biomass and cell wall content of $M$. indicus grown in different media.

\begin{tabular}{lllll}
\hline & & \multicolumn{2}{c}{ Cell wall } \\
\cline { 3 - 5 } Medium & $\begin{array}{l}\text { Protein } \\
\text { (g/g biomass) }\end{array}$ & $\begin{array}{l}\text { N-acetyl } \\
\text { glucosamine } \\
\text { (g/g AIM) }\end{array}$ & $\begin{array}{l}\text { Glucosamine } \\
\text { (g/g AIM) }\end{array}$ & $\begin{array}{l}\text { Phosphate } \\
\text { (g/g AIM) }\end{array}$ \\
\hline Lead-free & $0.51 \pm 0.01$ & $0.21 \pm 0.02$ & $0.16 \pm 0.01$ & $0.11 \pm 0.01$ \\
$\begin{array}{l}\text { With Lead } \\
(10 \mathrm{mg} / \mathrm{L})\end{array}$ & $0.47 \pm 0.01$ & $0.23 \pm 0.01$ & $0.19 \pm 0.01$ & $0.1 \pm 0.01$ \\
\hline
\end{tabular}

\subsection{Effect of lead on the biomass production}

The effect of lead on the biomass concentration for the three morphologies was studied, and the results are presented in Table 2. The presence of lead resulted in higher fungal biomass production in mostly filamentous and purely filamentous forms in the first and last stages of cultivation, compared with what obtained in the lead-free medium; however, an opposite trend was detected for the yeast-like morphology. Furthermore, in the first stage, the amount of the produced yeast-like biomass was the lowest in the presence of lead. For lead-free medium, the amount of the mostly-filamentous biomass was the lowest, while that of the yeast-like form was the highest. This was in agreement with the results reported by Sharifia et al. (2008) for cultivation of M. indicus in media containing no heavy metals.

Table 2.

Biomass produced in different media for the three morphologies of $M$. indicus

\begin{tabular}{lcccccc}
\hline \multirow{2}{*}{ Morphology } & \multicolumn{2}{c}{ First stage $(\mathrm{g} / \mathbf{L})$} & & \multicolumn{2}{c}{ Fifth stage $(\mathrm{g} / \mathbf{L})$} \\
\cline { 2 - 3 } & Lead-free & With lead & & Lead-free & With lead \\
\hline Purely filamentous & $2.52 \pm 0.08$ & $3.08 \pm 0.08$ & & $7.08 \pm 0.23$ & $7.60 \pm 0.21$ \\
Mostly filamentous & $1.88 \pm 0.05$ & $2.80 \pm 0.07$ & & $7.36 \pm 0.22$ & $7.40 \pm 0.23$ \\
\hline Purely yeast-like & $3.60 \pm 0.08$ & $2.61 \pm 0.09$ & & $7.36 \pm 0.21$ & $6.56 \pm 0.19$ \\
\hline
\end{tabular}

The reason for higher biomass production in the presence of lead could be the inhibition of some metabolites formation, e.g., ethanol and glycerol, and shifting the metabolism towards biomass formation (Taherzadeh and Karimi, 2011).

There is no study on the effect of heavy metals on biomass amount, but there are some reports indicating that the presence of some metal ions in cultivation medium affected the fungal growth (Bartnicki-Garcia and Nickerson, 1962; Arti and Guleria, 2013). The fungus Lentinus cladopus was cultivated in the presence of five metal ions (iron, boron, manganese, molybdenum, and zinc). It was observed that the amount of produced biomass was decreased with increasing iron and boron concentration from 1 to $2 \mathrm{mg} / \mathrm{L}$, while the biomass concentration was increased by increasing zinc, manganese, and molybdenum concentration in the same range (Arti and Guleria, 2013).
3.4. Isotherm study and the effect of lead on biosorption capacity of $M$. indicus

The equilibrium biosorption capacity $v s$. equilibrium concentrations is presented in Figure 3. It was observed that the biosorption capacity of biomass was increased with increasing metal ion concentration. A similar trend was also observed for copper biosorption by chitosan extracted from M. indicus cell wall (Behnam et al., 2015b).

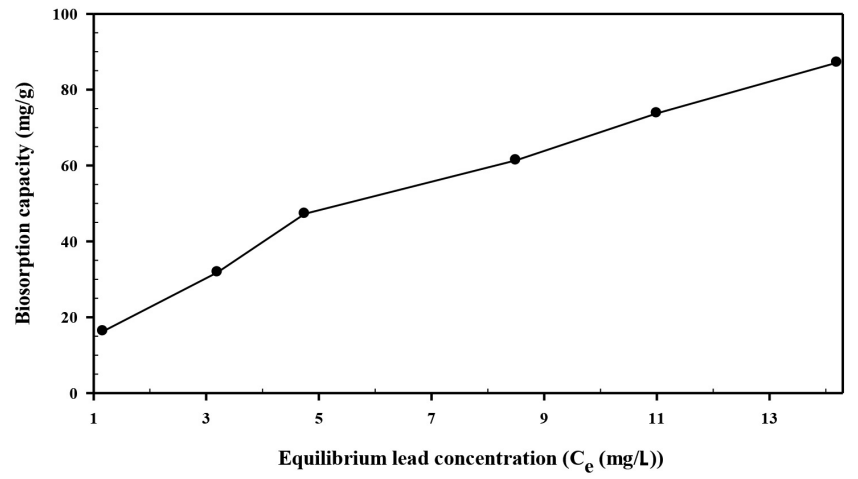

Fig.3. Equilibrium biosorption of lead ions by M. indicus biomass.

In order to describe the adsorption isotherm, Langmuir and Freundlich models were used, and the results are presented in Table 3. Both models could successfully describe the isotherm data, as the corresponding correlation factors were high $\left(\mathrm{R}^{2}>0.99\right)$. Furthermore, the maximum adsorption capacity obtained by Langmuir model was $117 \mathrm{mg} / \mathrm{g}$, indicating the high potential of M. indicus biomass for lead removal from the contaminated media. It was previously shown that Langmuir and Freundlich models predicted the isotherm data obtained by the dead biomass of $M$. indicus in purely filamentous form and the obtained value of $q_{\max }$ was $22 \mathrm{mg} / \mathrm{g}$ (Javanbakht et al., 2011), revealing the lower ability of the dead biomass for lead removal.

Table 3.

Isotherm models' constants for biosorption of $\mathrm{Pb}^{2+}$ by $M$. indicus biomass.

\begin{tabular}{lll}
\hline Model & Parameters & Value \\
\hline & $R^{2}$ & \\
Langmuir & $q_{\max }(\mathrm{mg} / \mathrm{g})$ & 0.9919 \\
& $K(\mathrm{~L} / \mathrm{mg})$ & 117.7 \\
& & 0.13 \\
& $R^{2}$ & \\
Freundlich & $n$ & 0.9931 \\
& $K_{\mathrm{F}}\left((\mathrm{mg} / \mathrm{g}) /(\mathrm{mg} / \mathrm{L})^{1 / \mathrm{n}}\right)$ & 1.49 \\
& & 15.00 \\
\hline
\end{tabular}

Lead removal was also investigated within five consecutive stages with the initial lead concentration of $300 \mathrm{mg} / \mathrm{L}$ for different morphologies of $M$. indicus, and the results are presented in Table 4. In all stages, different morphologies of $M$. indicus adsorbed $97-99 \%$ of the lead ions, and the biosorption capacities of all morphologies did not show considerable differences among the stages, which would indicate that the biomass was capable of adsorbing lead ions within several stages.

Table 4.

Final lead concentrations (mg/L) throughout the five consecutive cultivation stages.

\begin{tabular}{lccccc}
\hline \multirow{2}{*}{$\begin{array}{l}\text { Fungal } \\
\text { morphology }\end{array}$} & $\mathbf{5}$ & $\mathbf{2}$ & $\mathbf{3}$ & $\mathbf{4}$ & $\mathbf{5}$ \\
\cline { 2 - 6 } & $\mathbf{1}$ & $3.0 \pm 0.07$ & $3.4 \pm 0.09$ & $4.5 \pm 0.12$ & $6.2 \pm 0.16$ \\
\hline Purely filamentous & $2.7 \pm 0.07$ & $2.8 \pm 0.07$ & $3.12 \pm 0.08$ & $4.2 \pm 0.11$ & $6.13 \pm 0.15$ \\
Mostly filamentous & $2.5 \pm 0.07$ & $2.8 \pm 0.08$ & \\
Purely yeast-like & $4.5 \pm 0.13$ & $2.4 \pm 0.06$ & $6.3 \pm 0.16$ & $3.46 \pm 0.08$ & $2.8 \pm 0.08$ \\
\hline
\end{tabular}




\subsection{Effect of lead on sugar consumption and ethanol production}

Glucose consumption rate by different morphologies of $M$. indicus was studied, and the results are presented in Table 5. The presence of lead decreased the glucose consumption rate, indicating that it took a longer time for complete consumption of glucose by all morphologies in the contaminated media. Furthermore, the consumption rate by all morphologies at the fifth stage was lower than at the first one. In the presence of lead at the first stage, the time for complete consumption of glucose increased from 18 to $21 \mathrm{~h}$ for purely filamentous form and from 7 to $10 \mathrm{~h}$ for purely yeast-like form. Similar trend was also observed for the last stage in the presence of lead. Besides, in all stages, the fastest and the slowest glucose consumption rates were observed for the yeast-like form and the mostly filamentous form, respectively, in agreement with the results of Sharifia et al. (2008) obtained in the absence of heavy metals.

Table 5.

Time (h) for complete glucose consumption by different morphologies of M. indicus.

\begin{tabular}{lcccccc}
\hline \multirow{2}{*}{ Morphology } & \multicolumn{2}{c}{ First stage } & & \multicolumn{2}{c}{ Fifth stage } \\
\cline { 2 - 3 } \cline { 5 - 6 } \cline { 5 - 6 } & Lead-free & With lead & & Lead-free & With lead \\
\hline Purely filamentous & 18 & 21 & & 21 & 24 \\
Mostly filamentous & 20 & $22-23$ & & $22-23$ & $25-26$ \\
Purely yeast- like & 7 & 10 & & 15 & 18 \\
\hline
\end{tabular}

In a study performed by Lennartsson et al. (2009), the effect of acetic acid and furfural on glucose consumption by different morphologies of $M$. indicus was studied. They observed that the presence of these components also decreased glucose assimilation rate by all morphologies. For instance, the presence of furfural increased the time for complete consumption of glucose by purely yeast-like morphology from 3.75 to $19 \mathrm{~h}$.

Bioethanol yields ( $\mathrm{g}$ ethanol/g consumed glucose) by different morphologies were also obtained (Fig. 4). In the first stage, the highest (0.46 $\mathrm{g} / \mathrm{g})$ and the lowest $(0.41 \mathrm{~g} / \mathrm{g})$ bioethanol yields in the lead-free medium were obtained by mostly filamentous and purely filamentous form, respectively. The corresponding values for the media contaminated with lead ions were 0.43 and $0.38 \mathrm{~g} / \mathrm{g}$. The cell wall of filamentous cells are less thick, and the diffusion of sugars and ethanol is faster than through the yeast-like cells. On the other hand, the purely filamentous cells form compact pellets, and transfer of nutrients and metabolite through the pellets is slow, resulting in lower sugar uptake rate and ethanol productivity (Sharifia et al., 2008; Karimi and Zamani, 2013).

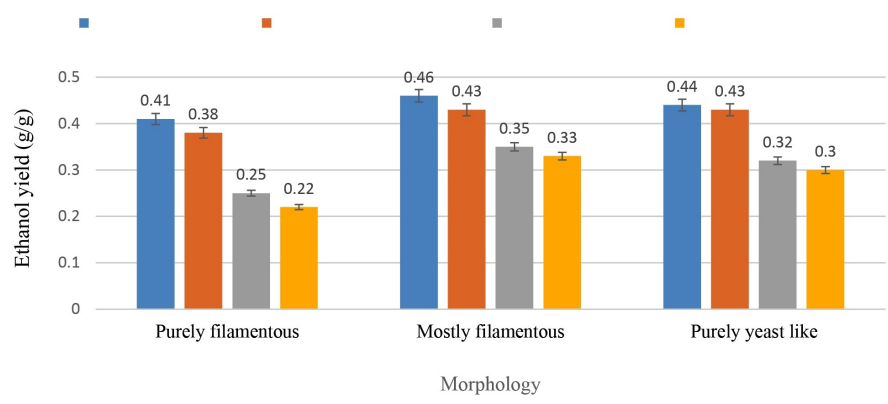

Fig.4. Ethanol yields by different morphologies in the presence and absence of lead.

In the last stage, the highest $(0.35 \mathrm{~g} / \mathrm{g})$ and the lowest $(0.25 \mathrm{~g} / \mathrm{g})$ ethanol yields in the lead-free medium were obtained by mostly filamentous and purely filamentous forms, respectively. The corresponding values for media containing $\mathrm{Pb}^{2+}$ ions were 0.33 and $0.22 \mathrm{~g} / \mathrm{g}$.

In order to analyze the data statistically, the analysis of variance (ANOVA) was performed, and the results obtained are presented in Table 6. Accordingly, the low p-value $(<0.05)$ indicated that there was a significant difference between ethanol yield in the first and the last stages, confirming a decrease in biomass ability for ethanol production through the consecutive stages.

Table 6.

Analysis of variance for dependency of ethanol yield on number of stages.

\begin{tabular}{lccccc}
\hline & Sum of Squares & df & Mean Square & F-value & P-value \\
\hline Between Groups & 0.051 & 1 & 0.051 & 31.104 & 0.000 \\
Within Groups & 0.016 & 10 & 0.002 & - & - \\
Total & 0.067 & 11 & - & - & - \\
\hline
\end{tabular}

Moreover, it was observed that the presence of lead in the cultivation medium, even at the high concentration of $300 \mathrm{mg} / \mathrm{L}$, did not inhibit ethanol production by $M$. indicus with different morphologies. However ethanol yields for all morphologies both in the first and last stages in the presence of lead were less than those obtained in lead-free medium. Furthermore, ethanol yields in the last stage were lower than the first one, indicating that the ability of $M$. indicus for ethanol production decreased after consecutive cultivations. In the absence of lead, the maximum yield of ethanol $(0.46 \mathrm{~g} / \mathrm{g})$ was obtained by filamentous form of $M$. indicus under anaerobic conditions, which was comparable with the results reported previously (Sharifia et al., 2008).

It is worth quoting that this was the first study on the effect of heavy metals on bioethanol production by $M$. indicus while there are some reports on $M$. indicus performance in media containing other inhibitors. For instance, Lennartsson et al. (2009) showed that for $M$. indicus in filamentous form under anaerobic conditions, $10 \mathrm{mg} / \mathrm{L}$ acetic acid decreased ethanol yield from $0.42 \mathrm{~g} / \mathrm{g}$ to $0.40 \mathrm{~g} / \mathrm{g}$, while $4.6 \mathrm{mg} / \mathrm{L}$ furfural decreased the yield to $0.41 \mathrm{~g} / \mathrm{g}$. The fungus consumed all furfural, while the amount of acetic acid was constant during the cultivation time.

\section{Conclusions}

The presence of lead in the cultivation media showed considerable effects on ethanol production by different morphologies of $M$. indicus Different forms of the fungus could grow in the presence of lead and consume all glucose. In all morphologies, the fungus produced ethanol in the presence of even high concentrations of lead within five consecutive cultivation stages, but with lower yields in comparison with those obtained in lead-free media. Ethanol yield and glucose consumption rate decreased from the first stage to the last, both in the presence and the absence of lead for all morphologies. Furthermore, all morphologies of $M$ indicus were capable of adsorbing considerable amounts of lead ions from the cultivation media while simultaneously producing bioethanol.

\section{Acknowledgements}

The authors would like to thank the Research Institute for Biotechnology and Bioengineering, Isfahan University of Technology Isfahan, for the financial support provided throughout this study.

\section{References}

[1] Aghbashlo, M., Tabatabaei, M., Dadak, A., Younesi, H., Najafpour, G., 2016. Exergy-based performance analysis of a continouus stirred bioreactor for ethanol and acetate fermentation from syngas via Wood-Ljungdahl pathway. Chem. Eng. Sci. 143, 36-46.

[2] Aksu, Z., 2002. Determination of the equilibrium, kinetic and thermodynamic parameters of the batch biosorption of nickel (II) ions onto Chlorella vulgaris. Process Biochem. 38(1), 89-99.

[3] Aryal, M., Liakopoulou-Kyriakides, M., 2014. Characterization of Mycobacterium sp. strain Spyr1 biomass and its biosorption behavior towards $\mathrm{Cr}$ (III) and $\mathrm{Cr}$ (VI) in single, binary and multi-ion aqueous systems. J. Chem. Technol. Biotechnol. 89(4), 559-568.

[4] Atri, N.S., Guleria, L., 2013. Evaluation of vitamin, phytohormone and trace element requirements of Lentinus cladopus lev. Int. J. Pharm. Pharm. Sci. 5, 40-42. 
[5] Baboukani, B.S., Vossoughi, M., Alemzadeh, I., 2012. Optimization of dilute-acid pretreatment conditions for enhancement sugar recovery and enzymatic hydrolysis of wheat straw. Biosyst. Eng. 111(2), 166-174.

[6] Bartnicki-Garcia, S., Nickerson, W.J., 1962. Nutrition, growth, and morphogenesis of Mucor Rouxii. J. Bacteriol. 84(4), 841-858.

[7] Bateni, H., Karimi, K., Zamani, A., Benakashani, F., 2014. Castor plant for biodiesel, biogas, and ethanol production with a biorefinery processing perspective. Appl. Energy. 136, 14-22.

[8] Behnam, S., Zamani, A., Karimi, K., Mehrabani-Zeinabad, A., 2015a. Copper removal from aqueous solutions using different fungal-based adsorbents: a comparative and detailed study. J. Dispersion Sci. Technol. 36(6), 866-876.

[9] Behnam, S., Karimi, K., Zamani, A., Mehrabani-Zeinabad, A., 2015b. Study on biosorption of copper ions by fungal chitosan: an alternative to shrimp chitosan. Biol. J. Microorganism. 3(12), 1-14.

[10] Çeribasi, I.H., Yetis, Ü., 2001. Biosorption of Ni (ii) and Pb(ii) by Phanerochaete chrysosporium from a binary metal system-kinetics. Water SA. 27(1), 15-20.

[11] Emtiazi, G., Satarii, M., Mazaherion, F., 2001. The utilization of aniline, chlorinated aniline, and aniline blue as the only source of nitrogen by fungi in water. Water. Res. 35(5), 1219-1224.

[12] Fasahati, P., Woo, H.C., Liu, J.J., 2015. Industrial-scale bioethanol production from brown algae: effects of pretreatment processes on plant economics. Appl. Energy. 139, 175-187.

[13] Guibal, E., Roulph, C., Le Cloirec, P., 1992. Uranium biosorption by a filamentous fungus Mucor miehei $\mathrm{pH}$ effect on mechanisms and performances of uptake. Water. Res. 26(8), 1139-1145.

[14] Hosseinpour, S., Aghbashlo, M., Tabatabaei, M., Khalife, E., 2016. Exast estamination of biodiesel cetane number $(\mathrm{CN})$ from its fatty acid methyl esters (FAMEs) profile using partial least square (PLS) adopted by artificial neural network (ANN). Energy Convers. Manage. 124, 389398.

[15] Javanbakht, V., Zilouei, H., Karimi, K., 2011. Lead biosorption by different morphologies of fungus Mucor indicus. Int. Biodeterior. Biodegrad. 65(2), 294-300.

[16] Karimi, K., Chisti, Y., 2015. Future of bioethanol. Biofuel Res. J. 2(1), 147-147.

[17] Karimi, K., Zamani, A., 2013. Mucor indicus: biology and industrial application perspectives: a review. Biotechnol. Adv. 31(4), 466-481.

[18] Lennartsson, P.R., Karimi, K., Edebo, L., Taherzadeh, M.J., 2009. Effects of different growth forms of Mucor indicus on cultivation on dilute-acid lignocellulosic hydrolyzate, inhibitor tolerance, and cell wall composition. J. Biotechnol. 143(4), 255-261.
[19] Lièvremont, D., Seigle-murandi, F., Benoit-guyod, J.L., 1998. Removal of PCNB from aqueous solution by a fungal adsorption process. Water. Res. 32(12), 3601-3606.

[20] Majumdar, S.S., Das, S.K., Chakravarty, R., Saha, T., 2010. A study on lead adsorption by Mucor rouxii biomass. Desalination. 251(1-3) 96-102.

[21] Mohammadi, M., Zamani, A., Karimi, K., 2012. Determination of glucosamine in fungal cell walls by high performance liquid chromatography (HPLC). J. Agric. Food. Chem. 60(42), 1051110515.

[22] Mohammadi, M., Zamani, A., Karimi, K., 2013. Effect of phosphate on glucosamine production by ethanolic fungus Mucor indicus. Appl. Biochem. Biotechnol. 171(6), 1456-1472.

[23] Naghdi, M., Zamani, A., Karimi, K., 2014. A sulfuric-lactic acid process for efficient purification of fungalchitosan with intact molecular weight. Int. J. Biol. Macromol. 63, 158-162.

[24] Orloski, M., 1991. Mucor Dimorphism. Microbiol. Rev. 55(2), 234 258.

[25] Shafiei, M., Karimi, K., Taherzadeh, M.J., 2011. Technoeconomical study of ethanol and biogas from spruce wood by NMMO-pretreatment and rapid fermentation and digestion. Bioresour. Technol. 102(17), 7879-7886.

[26] Sharifia, M., Karimi, K., Taherzadeh, M.J., 2008. Production of ethanol by filamentous and yeast-like forms of Mucor indicus from fructose, glucose, sucrose, and molasses. J. Ind. Microbiol. Biotechnol. 35(11), 1253-1259.

[27] Shroff, K., Vaidya, V.K., 2012. Effect of pre-treatments on the biosorption of Chromium (VI) ions by the dead biomass of Rhizopus arrhizus. J. Chem. Technol. Biotechnol. 87(2), 294-304

[28] Taherzadeh, M.J., Karimi, K., 2011. Fermentation inhibitors in ethanol processes and different strategies to reduce their effects, in Pandey, A. (Ed.), Biofuels. Elsevier Inc, pp. 287-311.

[29] Verduyn, C., Postma, E., Scheffers, W.A., Van Dijken, J.P., 1990 Physiology of Saccharomyces cerevisiae in anaerobic glucoselimited chemostat cultures. J. Gen. Microbiol. 136(3), 395-403.

[30] Yan, G., Viraraghavan, T., 2001. Heavy metal removal in a biosorption column by immobilized M. rouxii biomass. Bioresour. Technol. 78(3), 243-249.

[31] Yan, G., Viraraghavan., T., 2003. Heavy-metal removal from aqueous solution by fungus Mucor rouxii. Water. Res. 37(18), 4486 4496. 